\title{
Cognitive Performance among Cognitively Healthy Adults Aged 30-100 Years
}

\author{
Minna Alenius $^{a}$ Sanna Koskinen ${ }^{a} \quad$ Ilona Hallikainen $^{\mathrm{b}} \quad$ Tiia Nganduc $^{c}$ \\ Jari Lipsanen $^{a}$ Päivi Sainio $^{d}$ Annamari Tuulio-Henriksson ${ }^{a, e}$ \\ Tuomo Hänninen ${ }^{b, f}$ \\ aDepartment of Psychology and Logopedics, Helsinki University, Helsinki, Finland; \\ ${ }^{b}$ Institute of Clinical Medicine/Neurology, University of Eastern Finland, Kuopio, Finland; \\ 'Public Health Promotion Unit, National Institute for Health and Welfare, Helsinki, Finland; \\ ${ }^{\mathrm{d}}$ Aging, Disability and Functioning Unit, National Institute for Health and Welfare, \\ Helsinki, Finland; e Research Department, Social Insurance Institution, Helsinki, Finland; \\ fDepartment of Neurology, Kuopio University Hospital, Kuopio, Finland
}

\author{
Keywords \\ Consortium to Establish a Registry for Alzheimer's Disease · Cognitive abilities screening \\ instrument · Cognitive ageing · Education
}

\begin{abstract}
Background/Aims: To detect cognitive decline in older adults, measures of verbal fluency and verbal memory are widely used. Less is known about performance in these measures in younger persons or according to education level and gender. We investigated cognitive performance according to age, education and gender among cognitively healthy adults aged 30-100 years. Methods: The study population comprised 4,174 cognitively healthy persons participating in the nationally representative Finnish Health 2011 survey. Cognitive assessment included verbal fluency, word list memory, word list recall and word list savings from the Consortium to Establish a Registry for Alzheimer's Disease neuropsychological battery. Results: Total variance in the cognitive test performance explained by age, education and gender varied from 12.3 to $31.2 \%$. A decreasing trend in cognitive performance existed in all subtests by advancing age, with differences appearing between 50 and 55 years. Persons with the highest-education level performed best for all measures. For the participants $<55$ years, education explained part of the variance, while age and gender did not. Conclusions: When assessing cognition, age and education should be accounted for in more detail in research and clinical practice. Additionally, the cohort effect and its potential impact on the renewal cycle of future normative values for cognitive tests should be considered.
\end{abstract}


Alenius et al.: Cognition by Age, Gender and Education in Healthy Adults

\section{Introduction}

Ageing is the main risk factor for dementia: for people aged 60 years and over, the prevalence of dementia increases exponentially by age [1]. Many studies have evaluated cognitive changes related to normal ageing. With normal ageing, the processing speed often slows down, which may have implications for a variety of cognitive domains [2]. Ageing may also impair memory retrieval [2] that is the ability to access newly learned information. Laterborn cohorts may have better cognitive performance than earlier-born cohorts when investigated at the same age [3]. Therefore, in addition to age there is also a need to investigate the association between age and cognition in newer cohorts.

Besides ageing, different demographic characteristics are related to cognitive performance. Higher education is associated with a lower risk of dementia [4-7]. Among persons with higher education, educational attainment may increase cognitive reserve; consequently, more age-related brain changes or Alzheimer's disease (AD) pathology can accumulate before the manifestation of cognitive symptoms [8]. Additionally, it has been proposed that among persons with higher education, subjective and objective cognitive test evaluations can be used to predict future dementia well, but lower education makes this prediction more difficult [9].

In some regions, such as Western Europe, the prevalence of dementia is lower for men than women [1]. Gender differences in cognition appear to vary across birth cohorts and regions; the differences are associated with changes in living conditions and educational opportunities that different cohorts are exposed to during their formative years [10].

The Consortium to Establish a Registry for Alzheimer's Disease (CERAD) was established to standardize and validate measures for the assessment of AD. The CERAD neuropsychological battery (CERAD-nb) was developed to measure early cognitive impairment in AD [11] and it is widely used in different countries and languages [12]. The CERAD-nb was translated into Finnish in 1999 [13]. Finnish normative values based on a random sample of 321 cognitively normal older adults (aged 63-79) were published in 2007 [14]; later publications included cutoff scores having sensitivity and specificity considerations $[15,16]$.

Verbal fluency tasks measure verbal production, semantic memory and language [17]. Semantic fluency deficits typically appear in persons with AD [18] or amnestic mild cognitive impairment [19]. The verbal fluency task in CERAD-nb (VFA) utilizes semantic animal category fluency [11]. Several recent studies have suggested that age [14, 20-23] and education [14, 20-24] account for much variance in VFA performance. Few studies, however, link gender to VFA [24, 25], with most studies showing no association [14, 20, 22].

Verbal memory measures are used to discriminate normal aging from AD and mild cognitive impairment [11,26-29]. To examine these characteristics, the CERAD-nb uses word list memory (WLM), word list recall (WLR), word list saving (WLS) and word list recognition $[11,30]$. WLR is usually the best overall CERAD-nb measure to identify patients with early AD [26-28]. Previous studies link higher education and lower age with better verbal memory performance [14, 24, 25]; for gender, however, results are inconsistent [14, 25]. Recent discoveries in WLM and WLR performance also include a cohort effect, with improvements between the earliest- and latest-born cohorts [31].

Many studies report data on the efficiency of verbal fluency and verbal memory measures in detecting cognitive decline in older adults [26-30]. Few studies have included younger participants. One study showed VFA performance linearly declines with age from early life [20], and another study showed that people with higher levels of education or younger age attain better VFA scores [22]. Little is known about population-based performance differences in these tests within a wider age range, or with a sufficiently large sample to cover different education levels. Normative data with wider age and education range are needed 
[32]. For use in clinical practice, population-based samples may give more meaningful reference values than smaller selected samples [24]. Our study aims to evaluate cognitive performance according to age, education and gender in a large nationally representative sample of cognitively healthy adults aged 30-100 years.

\section{Material and Methods}

\section{Participants}

The study data derived from the Finnish nationwide population-based health examination survey (Health 2011), which was carried out in 2011 and included adults aged 18 or older. Details of the design, implementation and results of the Health 2011 survey have been previously reported $[33,34]$. The Health 2011 survey protocol was approved by the Coordinating Ethics Committee at the Hospital District of Helsinki and Uusimaa (reference 45/13/03/00/11). All participants provided their written informed consent.

Invited to the Health 2011 survey were 7,964 participants aged 30 or older. These participants had partaken in a similar national Health 2000 survey 11 years earlier. Of these persons, 4,664 participated in the health examination. Altogether, 4,544 persons were assessed using the CERAD-nb verbal fluency and verbal memory measures. In addition, the health interview involving participants aged 55 or older included a Six-Item Screener (SIS) that has been validated as a short version of the Mini Mental State Examination [35, 36]. Participant exclusion from the current analyses related to: incomplete CERAD-nb information $n=41$; missing information on education $n=36$; conditions affecting cognitive performance (stroke, psychosis, Parkinson's, AD, vascular cognitive impairment, substance abuse, intellectual disability, encephalopathy) altogether $n=214$; and potential dementia (SIS score less than 3) $n=79$. Consequently, the final sample for our study comprised a total of 4,174 participants.

Information on self-reported education was categorized into three levels [33]. The lowest- education level included persons with no vocational training (beyond a vocational course or job training) and who had not taken a matriculation examination. The middleeducation level included persons who had completed vocational school (regardless of basic education), and those who had passed a matricular examination but had no vocational training. The highest- education level included persons with degrees from higher vocational institutions, polytechnics and universities.

For the younger generations, age was categorized into 10 -year age groups. For participants 55 years or older, age was categorized into 5-year age groups, as the risk for dementia after 60 years doubles every 6.5 years in Western and Central Europe [1]. The whole sample was divided into two subsamples: participants under 55 years (the group $<55)(n=1,989)$, and participants over 55 years (the group $\geq 55)(n=2,185)$. Creation of the latter group enabled comparisons with other studies focusing on older people [14-16, 23-25, 30].

\section{Procedures and Measurements}

Participants of the Health 2011 attended a comprehensive health examination and health interview given by trained nurses in a health center near each participant's place of residence $[33,34]$. The concise examination was performed at home if the participant was unable to attend the health examination site. Selected parts of the CERAD battery, namely VFA, WLM and WLR, were included in the study protocol. In the VFA, the participant was asked to generate as many examples of animals as possible in $60 \mathrm{~s}$. The WLM task included three trials to learn a list of 10 unrelated words presented each time in a different order. The participant read the words aloud and was asked to recall as many words as possible at the end of each learning trial. The recalled words from each trial were summed to produce the WLM score. 
Table 1. Number of participants according to age, gender and education $(n=4,174)$

\begin{tabular}{|c|c|c|c|c|c|c|c|c|}
\hline \multirow{3}{*}{$\begin{array}{l}\text { Age, } \\
\text { years }\end{array}$} & \multicolumn{6}{|c|}{ Education } & \multicolumn{2}{|c|}{ Gender } \\
\hline & \multicolumn{2}{|c|}{ lowest } & \multicolumn{2}{|c|}{ middle } & \multicolumn{2}{|c|}{ highest } & \multirow[t]{2}{*}{ men } & \multirow[t]{2}{*}{ women } \\
\hline & men & women & men & women & men & women & & \\
\hline $30-39$ & 11 & 6 & 108 & 91 & 116 & 229 & 235 & 326 \\
\hline $40-49$ & 25 & 27 & 189 & 166 & 183 & 331 & 397 & 524 \\
\hline $50-54$ & 40 & 30 & 115 & 101 & 80 & 141 & 235 & 272 \\
\hline 55-59 & 54 & 60 & 100 & 102 & 78 & 120 & 232 & 282 \\
\hline $60-64$ & 86 & 83 & 102 & 84 & 78 & 123 & 266 & 290 \\
\hline $65-69$ & 71 & 92 & 64 & 64 & 45 & 77 & 180 & 233 \\
\hline $70-74$ & 68 & 103 & 43 & 44 & 33 & 40 & 144 & 187 \\
\hline$\geq 75$ & 76 & 146 & 46 & 40 & 28 & 35 & 150 & 221 \\
\hline Total & 431 & 547 & 767 & 692 & 641 & 1,096 & 1,839 & 2,335 \\
\hline
\end{tabular}

After VFA and WLM tasks, a handgrip test was administered before WLR. The WLR part of the test was presented $5 \mathrm{~min}$ after the third learning trial. The participant was asked to recall as many words as possible. The WLS score was calculated as a percentage of WLR to learning trial 3 in WLM.

\section{Statistical Analyses}

The analyses were conducted using SPSS complex samples add-on software, which accounts for sampling design. Weighting the observations produced estimates representative of the Finnish adult population by reducing the nonresponse bias [33, 34].

Differences in cognitive performance between education levels, age groups, and genders, along with interactions between these variables, were evaluated by analyses of variance (ANOVA). Evaluation of the effects involved the ANOVA model effect, $R^{2}$ of each analysis and a combination of each. Performance of pairwise comparisons used Bonferroni correction. A $p$ value $<0.05$ was considered statistically significant, and corrected $p$ values were used throughout the study. All statistical analyses were performed using SPSS 24.0 or 25.0 with complex sample add-on (IBM Corp. Released 2015; IBM SPSS Statistics for Macintosh, version 24.0; Armonk, NY, IBM Corp.).

\section{Results}

Table 1 presents the number of participants by age, education and gender ( $56 \%$ women), and Table 2 presents their education in years of formal education.

Table 3 provides detailed descriptive statistics for all measured cognitive tasks by age, education and gender. Additionally, Figure 1 visualizes the overall performance.

For the whole sample, the overall mean for VFA was 24.9 words. Participants with higher education performed better than those with lower education $(p<0.001)$, and younger participants outperformed older participants $(p<0.001)$ (Table 3 and Fig. 1). The main effect of gender was not significant ( $p=0.893$ ); however, interaction existed between education and gender $(p=0.040)$ : among those with the highest education, men performed better than women. 
Table 2. Education in years (mean, standard deviation and median) by age, gender and education

\begin{tabular}{|c|c|c|c|c|c|c|c|}
\hline \multirow[t]{3}{*}{ Age, years } & & \multicolumn{6}{|c|}{ Education } \\
\hline & & \multicolumn{2}{|c|}{ lowest } & \multicolumn{2}{|c|}{ middle } & \multicolumn{2}{|c|}{ highest } \\
\hline & & men & women & men & women & men & women \\
\hline \multirow[t]{3}{*}{ 30-39 } & mean & 11 & 10 & 13 & 14 & 17 & 17 \\
\hline & SD & $(1.8)$ & (1.3) & $(2.3)$ & $(2.1)$ & $(2.5)$ & $(2.3)$ \\
\hline & median & 11 & 10 & 12 & 13 & 17 & 17 \\
\hline \multirow[t]{3}{*}{$40-49$} & mean & 10 & 11 & 12 & 13 & 17 & 16 \\
\hline & SD & $(1.0)$ & (1.9) & $(1.8)$ & $(2.1)$ & $(2.9)$ & $(3.0)$ \\
\hline & median & 9 & 10 & 12 & 13 & 16 & 16 \\
\hline \multirow[t]{3}{*}{ 50-54 } & mean & 11 & 9 & 12 & 13 & 16 & 16 \\
\hline & SD & $(2.2)$ & $(1.5)$ & $(2.2)$ & $(2.0)$ & $(3.4)$ & $(3.2)$ \\
\hline & median & 10 & 9 & 12 & 13 & 17 & 15 \\
\hline \multirow[t]{3}{*}{ 55-59 } & mean & 10 & 9 & 12 & 12 & 16 & 15 \\
\hline & & $(1.8)$ & $(1.8)$ & $(2.1)$ & $(2.1)$ & $(3.5)$ & $(3.0)$ \\
\hline & median & 9 & 9 & 12 & 12 & 16 & 15 \\
\hline \multirow[t]{3}{*}{$60-64$} & mean & 9 & 9 & 11 & 11 & 17 & 15 \\
\hline & SD & $(2.1)$ & $(1.4)$ & $(2.0)$ & $(2.1)$ & $(4.0)$ & $(3.5)$ \\
\hline & median & 8 & 9 & 11 & 11 & 16 & 15 \\
\hline \multirow[t]{3}{*}{$65-69$} & mean & 8 & 9 & 11 & 11 & 15 & 15 \\
\hline & SD & $(1.2)$ & $(1.8)$ & $(2.3)$ & $(2.6)$ & $(3.2)$ & $(3.0)$ \\
\hline & median & 8 & 8 & 11 & 10 & 15 & 15 \\
\hline \multirow[t]{3}{*}{$70-74$} & mean & 8 & 8 & 10 & 11 & 16 & 15 \\
\hline & SD & $(1.9)$ & (1.9) & $(2.1)$ & $(2.4)$ & $(3.8)$ & $(3.7)$ \\
\hline & median & 8 & 8 & 10 & 11 & 17 & 15 \\
\hline \multirow[t]{3}{*}{$\geq 75$} & mean & 7 & 7 & 11 & 10 & 14 & 12 \\
\hline & $\mathrm{SD}$ & (1.8) & (1.9) & $(2.6)$ & $(2.3)$ & $(4.1)$ & $(3.2)$ \\
\hline & median & 7 & 7 & 10 & 10 & 14 & 13 \\
\hline
\end{tabular}

There was no information of education in years for 386 participants, out of whom roughly half were women, and education was divided into all three education levels almost equally. But for age, the group aged 30-39 had roughly double the size (31\% of all) compared to the other groups.

The overall mean of WLM was 21.8 words. Participants with higher education performed better than those with lower education $(p<0.001)$, and younger participants outperformed older participants $(p<0.001)$ (Table 3 and Fig. 1). Further, women outperformed men $(p<$ $0.001)$. A three-way interaction existed between education, age and gender $(p=0.006)$.

The overall mean for WLR was 7.6 words. Participants with higher education performed better than those with lower education $(p<0.001)$, younger participants outperformed older participants $(p<0.001)$, and women outperformed men $(p<0.001)$. The overall mean for WLS was $88.1 \%$. Also, WLS participants with higher education performed better than those with lower education $(p<0.001)$, younger participants outperformed older participants $(p<$ 0.001 ) (Fig. 1 and Table 3), and women outperformed men $(p<0.001)$. Age and education interacted regarding WLS $(p=0.020)$, as the age effect was more pronounced with lower levels of education.

For the whole sample, the total variance explained by age, education and gender was largest for WLM (31.2\%) and WLR (28.2\%). For VFA, it was $15.8 \%$ and for WLS $12.3 \%$. For the group $\geq 55$, the effect sizes were similar to the whole sample; however, for the group $<55$ demographic variables explained substantially less of the variance in cognitive performance (Table 4). 
Dementia

and Geriatric

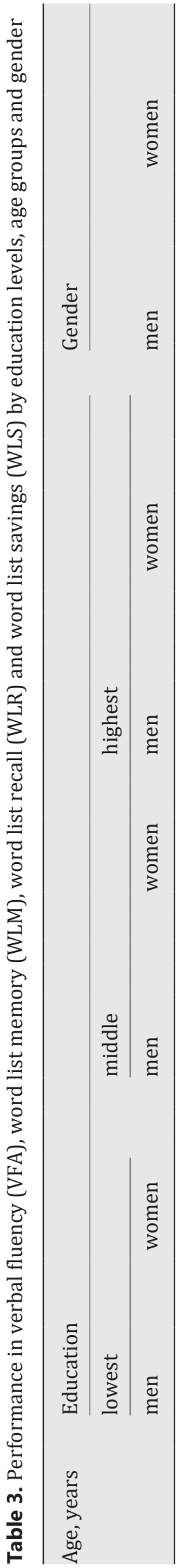

อกำ 包包包包包

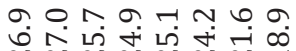

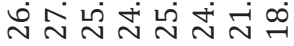

โ็กฺกสโล

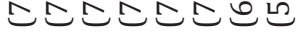

$0.0 . t \pi 04 \pi m$

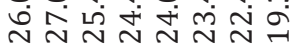

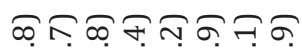
ف

ט. 0 . N

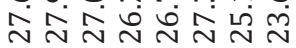

อกดேสโลส స્ડી

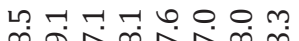

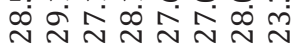

กด็ હ

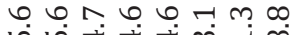

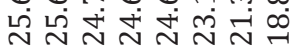

สกำลสอ

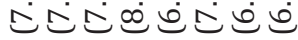

พ⿻ $\infty$ m

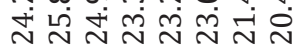

न6อำ ن்

ㄱ. 궁 เป็

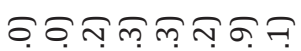

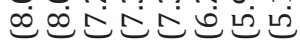

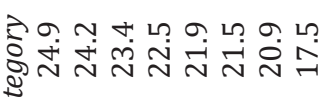
范

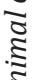

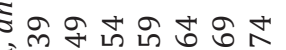

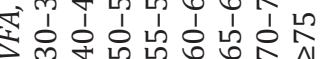

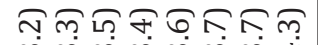
ल्र

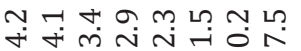

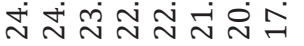

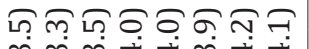
क्रृ

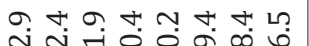
ลำ

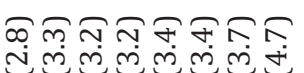

$\sim \operatorname{Ln} 00 \mathrm{~N}+\mathrm{N}$

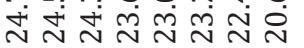

๓नสอดสอก త్ర

๑ นก ก m กั่

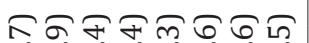

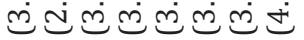

サก

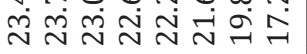

กิกล์ ल्र

○ $\infty$ 느 ᄂํ กั่

อำอำดว 包过过过

o o n m ลัง ํํำ

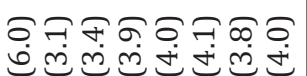

mำ กั

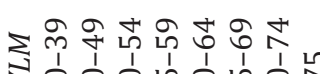

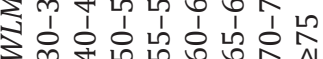

กํำ

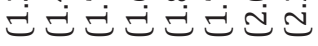
๑

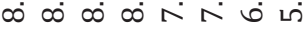

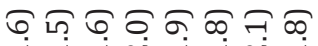

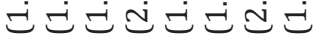

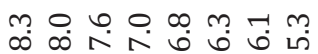

สำรดศดส ت己

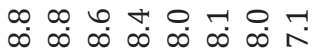

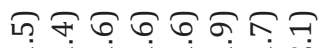

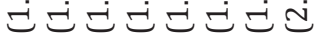

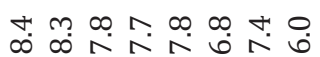
โ็ลกロ 巳己巳巳巳巳寸己 ma

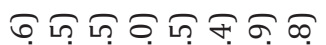

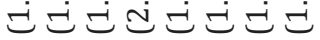

는 느

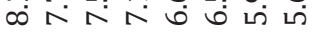

อำ주음

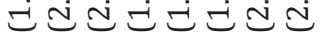

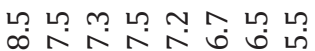
ํำำำร

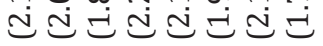

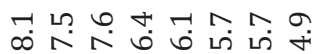

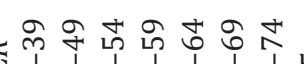

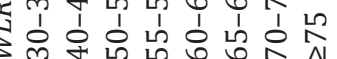

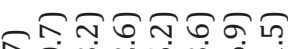

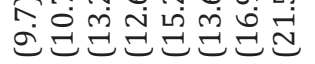

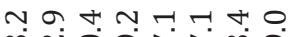
ภু ুু

ศสอสำ

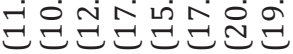
m เก 0 ด 0 ○ m

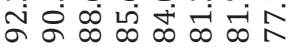

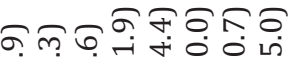

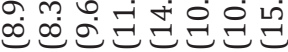

a. mo

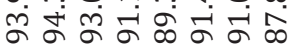

กำ

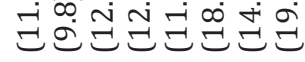

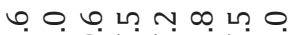
สู่

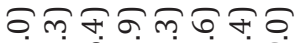

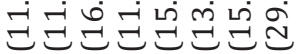
t m $00 N m \in 0$ नून ळ

โคกสโอกล

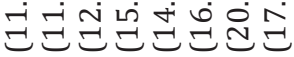

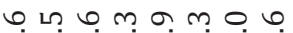
๙ूळ

ว

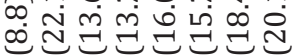

$\infty \sigma$. ல்

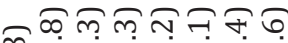

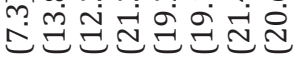

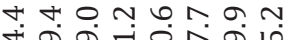

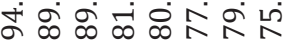

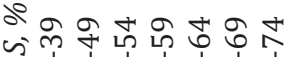

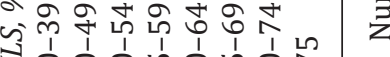

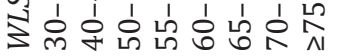




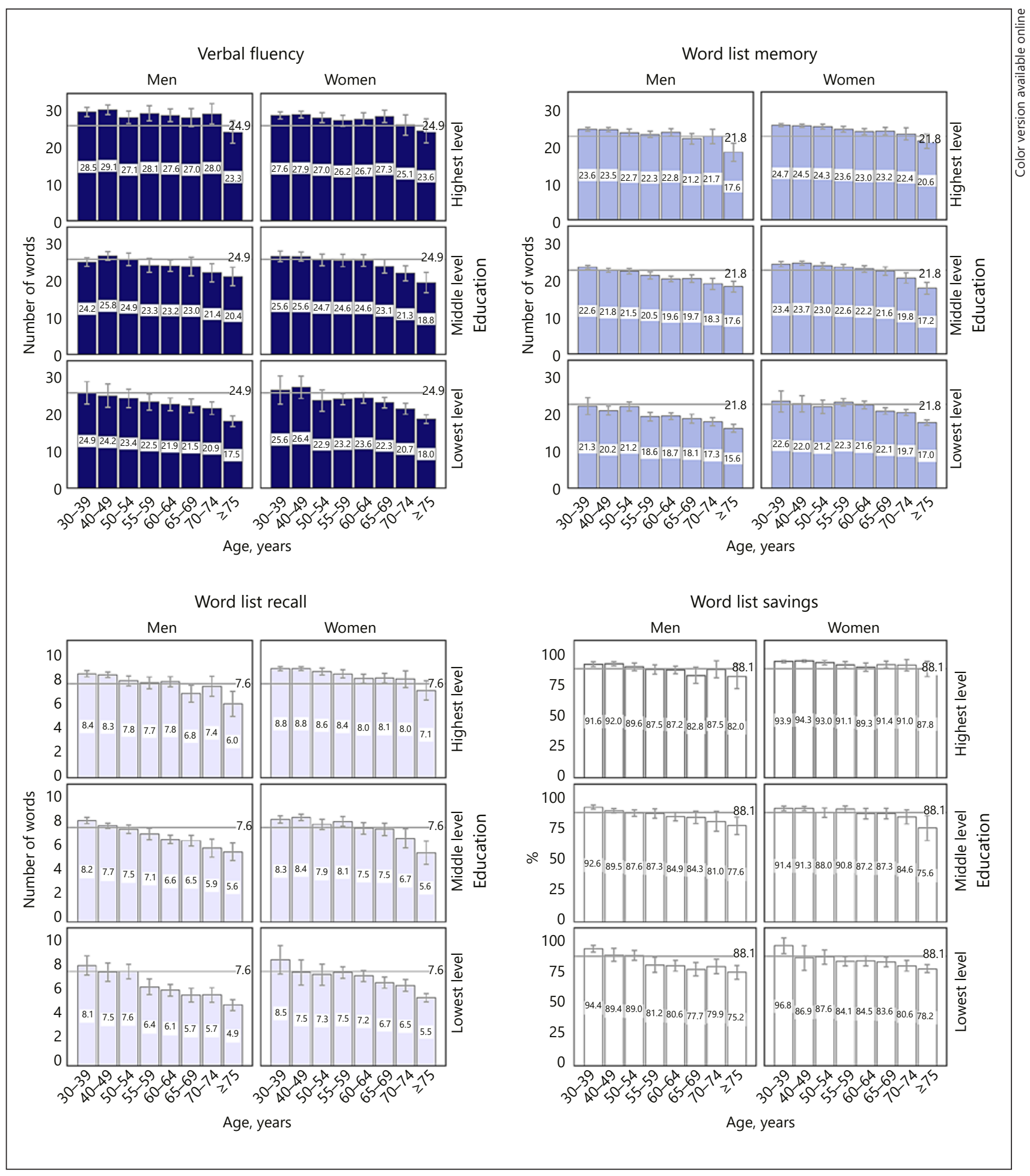

Fig. 1. Cognitive performance presented by means and $95 \%$ confidence intervals (indicated by error bars). Grey lines indicate overall mean of each variable. 
Alenius et al.: Cognition by Age, Gender and Education in Healthy Adults

Table 4. Proportion of variance in cognitive performance (\%) for verbal fluency (VFA), word list memory (WLM), word list recall (WLR) and word list savings (WLS) explained by age, education and gender

\begin{tabular}{lccll}
\hline & $\begin{array}{l}\text { Total effect } \\
\text { size of age, } \\
\text { education, } \\
\text { gender }\end{array}$ & $\begin{array}{l}\text { Age, } \\
\text { independent } \\
\text { effect }\end{array}$ & $\begin{array}{l}\text { Education, } \\
\text { independent } \\
\text { effect }\end{array}$ & $\begin{array}{l}\text { Gender, } \\
\text { independent } \\
\text { effect }\end{array}$ \\
\hline Whole sample & & & & \\
VFA & 15.8 & 4.3 & 5.1 & - \\
WLM & 31.2 & 11.2 & 5.0 & 3.2 \\
WLR & 28.2 & 11.3 & 3.5 & 2.2 \\
WLS & 12.3 & 4.8 & 1.5 & 0.5 \\
Subpopulation & $<55$ years & & & \\
VFA & 5.2 & 0.6 & 4.0 & - \\
WLM & 11.0 & 0.5 & 4.9 & 0.03 \\
WLR & 8.2 & 0.1 & 2.7 & 0.2 \\
WLS & 3.8 & 1.0 & 0.9 & 0 \\
Subpopulation & 255 years & & & \\
VFA & 17.2 & 5.4 & 7.4 & - \\
WLM & 27.8 & 10.7 & 6.7 & 4.6 \\
WLR & 22.0 & 8.1 & 5.6 & 3.7 \\
WLS & 7.3 & 2.1 & 2.4 & 0.9 \\
\hline
\end{tabular}

For the whole sample, age accounted for the highest proportion of variance for WLR at $11.3 \%$ and WLM at $11.2 \%$, and less for VFA at $4.3 \%$ and WLS at $4.8 \%$. Age had a small performance effect in the group $<55$.

In the whole sample, the Bonferroni-corrected pairwise comparisons between age groups indicated that some groups did not significantly differ from each other; subsequently, we created combined age groups. For VFA, the combined age groups could be summarized into 30-49 years, 50-69 years, 70-74 years and $\geq 75$ years, for WLM into 30-54, 55-64 years, $65-74$ years and $\geq 75$ years, for WLR into $30-49,50-54,55-64$ years, $65-74$ years and $\geq 75$ years and for WLS into $30-49,50-54,55-74$ years and $\geq 75$ years.

Education accounted for 5.1\% of variance for VFA, 5.0\% for WLM, 3.5\% for WLR and $1.5 \%$ for WLS. In the group $<55$, education accounted for more variance than age or gender (Table 4). In the whole sample, the Bonferroni-corrected pairwise comparisons between education levels indicated the lowest- and middle-education levels did not differ for VFA and WLS. For VFA and WLS, education levels were combined. The highest-education level differed $(p<0.001)$ for all cognitive outcomes. To clarify this, cognitive performance according to grouping of both age and education strata is presented in Figure 2.

Gender had only a minor effect on cognitive performance.

\section{Discussion}

We report on the scope of performance in both verbal fluency and verbal memory measures for a large representative sample of Finnish cognitively healthy participants aged between 30 and 100 years. Results from these cognitive tasks from the CERAD-nb indicated a decreasing trend in performance by advancing age, with differences beginning from the age of 50 or 55. For all used cognitive measures, persons with highest-education levels performed better than other educational groups. Persons with middle-education levels performed similarly to those with lowest-education levels regarding verbal fluency and verbal memory savings. For the group $<55$, education was the only demographic variable impacting cognitive performance. 


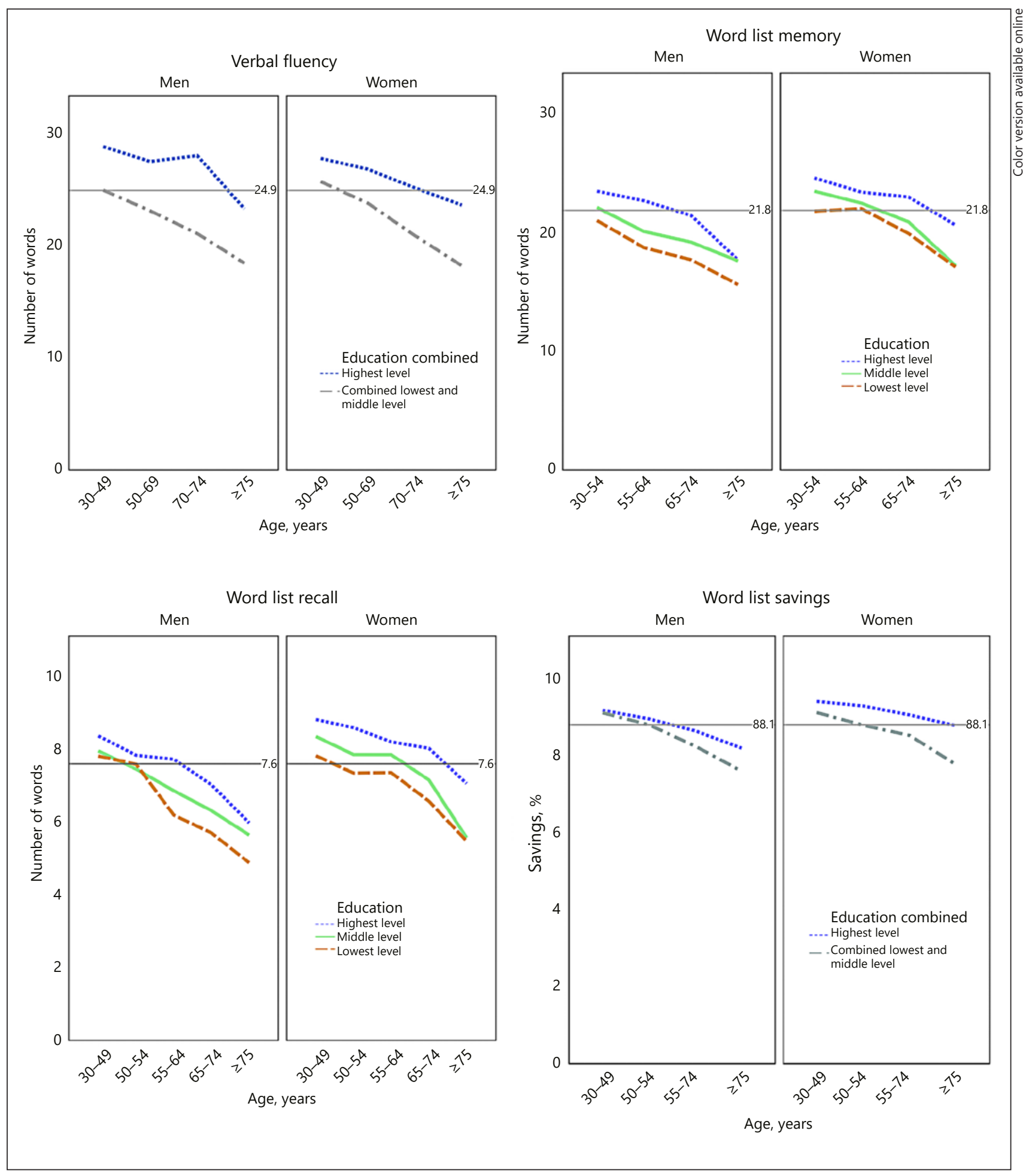

Fig. 2. Cognitive performance with combined groupings presented by means. Grey lines indicate overall mean of each variable. 
For the whole sample, the total effect size of demographic variables on performance was largest for WLM (31.2\%) and WLR (28.2\%), less for VFA (15.8\%) and least for WLS (12.3\%). Age affected performance for all variables, but not uniformly: for the group $<55$, age had only minimal effects on performance.

The mean level of cognitive performance of the group $\geq 55$ in our study was better than in previously published Finnish normative values [14-16]: VFA by roughly +2 words, WLM by +0.5 words, WLS by $+1 \%$ (WLR was previously not published), and the mean of education was 1.5 years higher. Additionally, the effect of age in our study was remarkably stronger for VFA and WLM, but less for WLS. The effect of education was almost the same as previously; for WLS, however, a new mild effect was found. The effect of gender was clearly smaller in our study. These differences between our study and the previous Finnish study [14,37] might reflect both ongoing changes in education levels of the Finnish population and the higher proportion of educated women in the group $\geq 55$ [38]. This agrees with the cohort effects in cognition described in recent studies $[3,10,31]$.

All variables indicated a noticeable effect of education on cognitive performance. We found a clear effect of education as the highest level differed from other levels for all cognitive measures. This result contrasts with the original CERAD-nb normative study by Welsh et al. [30] which indicated no differences between low and highly educated people on VFA, WLR and WLS. The small number of lower-educated participants in the original CERAD-nb norms [30] may partly explain this difference. For the group $\geq 55$, the age effect of VFA also differed from the original CERAD-nb norms that indicated a lack of age effect for both highly and lower educated groups. For verbal memory measures, the group $\geq 55$ had a similar decrease in performance with age, with women scoring better as in the original study. In our study, WLS showed a similar mild [30] but significant effect of age but also indicated a mild effect of education.

Our results are in line with some other earlier studies, which found that both age [14, 20-23, 25] and education [14, 20-25] affected VFA. In some studies, the magnitude of the age effect has been larger [22], while in others it has been closer to the $4 \%$ observed in our study $[14,23,25]$ except for one [24] which agrees with the original study with no age effect found [30]. The effect of education on VFA has been in several earlier studies [14, 22, 23, 25] close to our $5 \%$ finding. Gender had no independent effect on VFA in our study, which is in line with most previous studies [14, 20-22] but contrasts to one recent population-based study [24].

Our results of WLM, WLR and WLS are in line with a recent population-based study [24] with younger or more educated persons or women performing better. When comparing WLM and WLR to effect sizes of the elderly-focused large international study by Sosa et al. [25], the group $\geq 55$ had a similar education-level effect but the age effect in our study was almost double. Though the gender effect in our study was mild, it was 6 (WLR) to 9 (WLM) times larger than in the study of Sosa et al. [25], who found effects of only 0.6 and $0.5 \%$.

\section{Strengths and Limitations}

We used several measures of cognitive performance from data of a large, nationwide population-based study. The observations were weighted to produce estimates that represent the Finnish adult population by reducing the nonresponse bias. Due to health-related factors possibly affecting cognitive performance, medical exclusion criteria were used. The high prevalence of dementia in older age led to using a cognitive SIS to secure a cognitively healthy sample. The large sample size, large age range between 30 and 100, and coverage of all education levels are strengths of our study.

Various limitations are acknowledged in our study. First, performance may include a practice effect, as the participants had been assessed with the same tests 11 years earlier. Second, some early-state dementia participants may have been included in our study despite 
the use of SIS. Third, notwithstanding the large total sample, small group numbers existed for the number of persons in the lowest education level of age group 30-49, and the weighted number of highest-education level participants aged 70 and over. Consequently, these groups must be carefully interpreted. Fourth, conducting the WLR task after the handgrip test may produce slightly different results than using the traditional CERAD-nb protocol. Fifth, as for any population-based study, those who participate may have better health and cognitive function than nonparticipants.

\section{Conclusion}

In conclusion, our study on verbal fluency and verbal memory measures in a populationbased sample of cognitively healthy participants aged between 30 and 100 years indicates that age differences begin from the age of 50 or 55 . Furthermore, the highest-education level participants performed better than those with other education levels. The effect of demographic variables is smaller for the group $<55$. For the group $\geq 55$, age has the strongest impact on performance. Comparing our results to the previously published Finnish normative reveals a potential cohort effect. Future studies and clinical use of cognitive tasks to detect dementia require renewed and enlarged normative values for the group $\geq 55$. Also necessary is consideration of the cohort effect and its potential impact on the renewal cycle of future normative values.

\section{Acknowledgments}

We thank all of the Health 2011 participants and members of the Health 2011 study group for their cooperation, and data collection and management.

\section{Statement of Ethics}

The Health 2011 survey protocol was approved by the Coordinating Ethics Committee at the Hospital District of Helsinki and Uusimaa (reference 45/13/03/00/11). All participants provided their written informed consent.

\section{Disclosure Statement}

There are no conflicts of interest.

\section{References}

1 Prince M, Wimo A, Guerchet M, Ali G, Wu Y, Prina A. World Alzheimer Report 2015: The global impact of dementia. An analysis of prevalence, incidence, costs and trends. London: Alzheimer's Disease International; 2015.

2 Harada CN, Natelson Love MC, Triebel KL. Normal cognitive aging. Clin Geriatr Med. 2013 Nov;29(4):737-52.

3 Christensen K, Thinggaard M, Oksuzyan A, Steenstrup T, Andersen-Ranberg K, Jeune B, et al. Physical and cognitive functioning of people older than 90 years: a comparison of two Danish cohorts born 10 years apart [doi]. Lancet. 2013 Nov;382(9903):1507-13.

4 Hall CB, Derby C, LeValley A, Katz MJ, Verghese J, Lipton RB. Education delays accelerated decline on a memory test in persons who develop dementia. Neurology. 2007 Oct;69(17):1657-64.

5 Meng X, D'Arcy C. Education and dementia in the context of the cognitive reserve hypothesis: a systematic review with meta-analyses and qualitative analyses. PLoS One. 2012;7(6):e38268. 
6 Harrison SL, Sajjad A, Bramer WM, Ikram MA, Tiemeier H, Stephan BC. Exploring strategies to operationalize cognitive reserve: A systematic review of reviews. J Clin Exp Neuropsychol. 2015;37(3):253-64.

7 de Bruijn R F AG, Bos MJ, Portegies ML, Hofman A, Franco OH, Koudstaal PJ, et al. The potential for prevention of dementia across two decades: the prospective, population-based Rotterdam Study. BMC Med. 2015 Jul; 13(1):132.

8 Stern Y. Cognitive reserve in ageing and Alzheimer's disease. Lancet Neurol. 2012 Nov;11(11):1006-12.

9 Chary E, Amieva H, Pérès K, Orgogozo JM, Dartigues JF, Jacqmin-Gadda H: Short-versus long-term prediction of dementia among subjects with low and high educational levels. Alzheimers Dement. 2013 Sept;9(5):56271.

10 Weber D, Skirbekk V, Freund I, Herlitz A. The changing face of cognitive gender differences in Europe [doi]. Proc Natl Acad Sci USA. 2014 Aug;111(32):11673-8.

11 Morris JC, Heyman A, Mohs RC, Hughes JP, van Belle G, Fillenbaum G, Mellits ED, Clark C. The Consortium to Establish a Registry for Alzheimer's Disease (CERAD). I. Clinical and neuropsychological assessment of Alzheimer's disease. Neurology. 1989 Sep;39(9):1159-65.

12 Fillenbaum GG, van Belle G, Morris JC, Mohs RC, Mirra SS, Davis PC, et al. Consortium to Establish a Registry for Alzheimer's Disease (CERAD): the first twenty years. Alzheimers Dement. 2008 Mar;4(2):96-109.

13 Hänninen T, Pulliainen V, Salo J, Hokkanen L, Erkinjuntti T, Koivisto K, et al. Cognitive tests in diagnosing memory disorders and early dementia: CERAD-neuropsychological battery. Suomen Lääkärilehti. 1999;54: 1967-75. Finnish

14 Pulliainen T, Hänninen T, Hokkanen L, et al. Norms for use of the CERAD test battery in Finland. Suomen Lääkärilehti. 2007;12:1235-41. Finnish.

15 Hänninen T, Pulliainen V, Sotaniemi M, Hokkanen L, Salo J, Hietanen M, Pirttila T, Poyhonen M, Juva K, Remes A, Erkinjuntti T. Early detection of cognitive changes in memory diseases: new cut-off scores for the Finnish version of CERAD neuropsychological battery. Duodecim. 2010 Jan;126(17):2013-21.

16 Sotaniemi M, Pulliainen V, Hokkanen L, Pirttilä T, Hallikainen I, Soininen H, et al. CERAD-neuropsychological battery in screening mild Alzheimer's disease. Acta Neurol Scand. 2012 Jan;125(1):16-23.

17 Lezak MD, Howieson DB, Loring DW, editors. Neuropsychological assessment. 4th ed. New York: Oxford University Press; 2004.

18 Henry JD, Crawford JR, Phillips LH. Verbal fluency performance in dementia of the Alzheimer's type: a metaanalysis. Neuropsychologia. 2004;42(9):1212-22.

19 Teng E, Leone-Friedman J, Lee GJ, Woo S, Apostolova LG, Harrell S, et al. Similar verbal fluency patterns in amnestic mild cognitive impairment and Alzheimer's disease. Arch Clin Neuropsychol. 2013 Aug;28(5):40010.

20 Van der Elst W, Van Boxtel MP, Van Breukelen GJ, Jolles J. Normative data for the Animal, Profession and Letter M Naming verbal fluency tests for Dutch speaking participants and the effects of age, education, and sex. J Int Neuropsychol Soc. 2006 Jan;12(1):80-9.

21 Tallberg IM, Ivachova E, Jones Tinghag K, Ostberg P. Swedish norms for word fluency tests: FAS, animals and verbs. Scand J Psychol. 2008 Oct;49(5):479-85.

22 St-Hilaire A, Hudon C, Vallet GT, Bherer L, Lussier M, Gagnon JF, et al. Normative data for phonemic and semantic verbal fluency test in the adult French-Quebec population and validation study in Alzheimer's disease and depression. Clin Neuropsychol. 2016 Oct;30(7):1126-50.

23 Stokholm J, Jørgensen K, Vogel A. Performances on five verbal fluency tests in a healthy, elderly Danish sample. Neuropsychol Dev Cogn B Aging Neuropsychol Cogn. 2013;20(1):22-33.

24 Luck T, Pabst A, Rodriguez FS, Schroeter ML, Witte V, Hinz A, et al. Age-, sex-, and education-specific norms for an extended CERAD Neuropsychological Assessment Battery-Results from the population-based LIFE-AdultStudy. Neuropsychology. 2018 May;32(4):461-75.

25 Sosa AL, Albanese E, Prince M, Acosta D, Ferri CP, Guerra M, et al. Population normative data for the 10/66 Dementia Research Group cognitive test battery from Latin America, India and China: a cross-sectional survey. BMC Neurol. 2009 Aug;9(1):48.

26 Weissberger GH, Strong JV, Stefanidis KB, Summers MJ, Bondi MW, Stricker NH. Diagnostic Accuracy of Memory Measures in Alzheimer's Dementia and Mild Cognitive Impairment: a Systematic Review and MetaAnalysis. Neuropsychol Rev. 2017 Dec;27(4):354-88.

27 Welsh K, Butters N, Hughes J, Mohs R, Heyman A. Detection of abnormal memory decline in mild cases of Alzheimer's disease using CERAD neuropsychological measures. Arch Neurol. 1991 Mar;48(3):278-81.

28 Chen P, Ratcliff G, Belle SH, Cauley JA, DeKosky ST, Ganguli M. Cognitive tests that best discriminate between presymptomatic AD and those who remain nondemented. Neurology. 2000 Dec 26;55(12):1847-53.

29 Chen P, Ratcliff G, Belle SH, Cauley JA, DeKosky ST, Ganguli M: Patterns of cognitive decline in presymptomatic Alzheimer disease: A prospective community study. Arch Gen Psychiatry. 2001 Sep;58(9):853-8.

30 Welsh KA, Butters N, Mohs RC, Beekly D, Edland S, Fillenbaum G, Heyman A. The Consortium to Establish a Registry for Alzheimer's Disease (CERAD). V. A normative study of the neuropsychological battery. Neurology. 1994 Apr;44(4):609-14.

31 Dodge HH, Zhu J, Hughes TF, Snitz BE, Chang CH, Jacobsen EP, et al. Cohort effects in verbal memory function and practice effects: a population-based study. Int Psychogeriatr. 2017 Jan;29(1):137-48.

32 Daffner KR, Gale SA, Barrett AM, Boeve BF, Chatterjee A, Coslett HB, et al. Improving clinical cognitive testing: report of the AAN Behavioral Neurology Section Workgroup. Neurology. 2015 Sep;85(10):910-8. 
33 Koskinen S, Lundqvist A, Ristiluoma N: Terveys, toimintakyky ja hyvinvointi Suomessa 2011. Tampere: Terveyden ja Hyvinvoinnin Laitos; 2012.

34 Lundqvist A, Mäki-Opas T. Health 2011 Survey - Methods. Tampere: Finnish University Print; 2016.

35 Callahan CM, Unverzagt FW, Hui SL, Perkins AJ, Hendrie HC. Six-item screener to identify cognitive impairment among potential subjects for clinical research. Med Care. 2002 Sep;40(9):771-81.

36 Wilber ST, Lofgren SD, Mager TG, Blanda M, Gerson LW. An evaluation of two screening tools for cognitive impairment in older emergency department patients. Acad Emerg Med. 2005 Jul;12(7):612-6.

37 Tervo S, Kivipelto M, Hänninen T, Vanhanen M, Hallikainen M, Mannermaa A, et al. Incidence and risk factors for mild cognitive impairment: a population-based three-year follow-up study of cognitively healthy elderly subjects. Dement Geriatr Cogn Disord. 2004;17(3):196-203.

38 Official Statistics of Finland: Educational structure of population 2014 [e-publication]. Helsinki: Statistics Finland; 2014. 